\title{
Autologous Serum Eye Drops for Post-Chemical Injuries and Corneal Epithelial Defects
}

\author{
Mirjana A. Janicijevic-Petrovic ${ }^{1}$, Marko Petrovic $^{2}$, Dragan Vujic ${ }^{2}$, Katarina Janicijevic ${ }^{2}$, Andrijana Popovic $^{2}$ \\ ${ }^{1}$ Clinic of Ophthalmology, Clinical Centre of Kragujevac, Kragujevac, Serbia; ${ }^{2}$ Faculty of Medical Sciences, University of \\ Kragujevac, Kragujevac, Serbia
}

\author{
Citation: Janicijevic-Petrovic MA, Petrovic M, \\ Vujic D, Janicijevic K, Popovic A. Autologous \\ Serum Eye Drops for Post-Chemical Injuries \\ and Corneal Epithelial Defects. OA Maced \\ Med Sci. 2013 Dec 15; 1(1):45-49. \\ http://dx.doi.org/10.3889/oamjms.2013.009 \\ Key words: autologous serum; eye drops; \\ chemical injuries; corneal defects; treatment. \\ "Correspondence: Mirjana A. Janicijevic- \\ Petrovic. Clinic of Ophtalmology, Clinical Centre \\ of Kragujevac, Zmaj Jovina 30, Kragujevac, \\ Serbia. Mob: +38166013691. Fax: \\ +38134370073 . \\ E-mail:mira.andreja@yahoo.com \\ Received: 23-Aug-2013; Revised: 21-Sep- \\ 2013; Accepted: 26-Oct-2013; Online first: \\ 30-Oct-2013 \\ Copyright: (c) 2013 Janicijevic-Petrovic MA. \\ This is an open-access article distributed under \\ the terms of the Creative Commons Attribution \\ License, which permits unrestricted use, \\ distribution, and reproduction in any medium, \\ provided the original author and source are \\ credited. \\ Competing Interests: The authors have \\ declared that no competing interests exist.
}

\begin{abstract}
Aim: To evaluate success rate (efficacy, safety) in treatment of post-chemical injuries and corneal defects using autologous serum eye drops.

Material and Methods: Authors reviewed 93 patients (116 eyes) hospitalized in Clinic of ophthalmology from 2010 to 2013, who had post-causoma corneal defects that were nonresponsive to conventional treatment and were treated with serum therapy. Authors correlated time of epithelialization of defects with rate of epithelial healing.
\end{abstract}

Results: Authors investigated 93 patients (52 males, 41 females; aged 18 - 74) for treatment of corneal defects. Application of autologous serum therapy $56(48.28 \%)$ of 116 eyes was healed in an average time of 4 weeks. Among 116 eyes, epithelial defects healed in $4(3.45 \%)$ within 1 week, in additional $17(14.65 \%)$ in $1-2$ weeks, totalling $31(26.72 \%)$ within 3 weeks. Five eyes $(4.31 \%)$ completely healed at 5 week; three eyes $(2.59 \%)$ had subsequent healing of epithelial defect at 6 week; 56 eyes completely healed within one month, and the remaining eight eyes healed within 1.5 month.

Conclusion: Using serum therapy, it was managed to reduce time of healing from eleven weeks, which were necessary just couple years ago (before 2010) to four (maximum six) weeks to complete healing which are necessary today.

\section{Introduction}

Authors evaluate the efficacy and safety of autologous serum application in the treatment of postcausoma large and persistent corneal epithelial defects (time of closure of serious epithelial defects). Authors have established the protocol for the use of autologous serum in the ophthalmic practice (eye drop form) and reported as the relative new serum treatment for serious chemical eye injuries (causoma).

Chemical eye injuries are described as urgent trauma of eye (an urgent ophthalmologic pathology) and localized mostly on anterior segment with complications and residual sequels as corneal persistent epithelial defects, macular corneal opacities, dry eye, etc. Diagnostic procedure is easy, but therapy is complex.

The serum therapy has the biomechanical and biochemical properties similar to normal human tears. Tear film components, such as growth factors, fibronectin and vitamin A play the most important role in the functional proliferation, migration and differentiation of corneal and conjunctiva epithelium (epitheliotrophic effect on the ocular surface). The autologous serum contains immunoglobulin such as $\mathrm{lgG}$, lisozyme and supplemental factors, which endow it with certain bactericide and bacteriostatic effects. Serum exhibits characteristics which are similar to those of tears as regards the $\mathrm{pH}$ and the osmolarity. Like tears, it contains growth factors and bactericides which allow the treatment with topical autologous 
serum not only to humidify the eye surface, but to provide nutritional and growth factors necessary to maintain cellular feasibility in the epithelial repair processes and which reduce the risk of contaminations. Varying methods for the preparation and regime to application of autologous serum eye drops were used as well as different concentrations [1].

\section{Material and Methods}

Authors reviewed the medical records of the 116 eyes from the 93 patients which hospitalization in the our Clinic of ophthalmology from the $1^{\text {st }}$ June 2010 to the $1^{\text {st }}$ June 2013, who had post-causoma persistent corneal epithelial defects that were nonresponsive to conventional topical medical treatment, and were treated with autologous serum eye drops. Authors correlated the time duration of the epithelialization of defects due to usage of autologous serum eye drops with rate of epithelial healing.

Autologous serum was prepared from whole blood. Blood was obtained from the patients who were healthy and had no history of bacteremia, hepatitis, HIV, fungal infection, etc.

The patients applied the serum eye drops once every two hours for 30 and more days (50\% diluted of autologous serum).

All patients underwent the complete clinical ophthalmic examination. Patients were examined before treatment and on weekly basis during the treatment. Clinical examination included clinical evolution with fluorescing staining pattern of the cornea, Schemer's tests (normal, $10 \mathrm{~mm} / 5$ minutes or more) and tear film break-up time (normal, 10 seconds or more). Large and unusual epithelial defects were measured with the slit beam. Fluorescing staining scores $(\mathrm{FI}+++, \mathrm{FI}++, \mathrm{FI}+, \mathrm{FI}+/-$, $\mathrm{FI} \varnothing)$ as well as subjective symptom grading, were performed at hospitalization and weekly during the treatment.

In our study we extracted blood, which was distributed in tubes. Subsequently the tubes were left in vertical position at $22^{\circ} \mathrm{C}$ for about 2 hours to allow coagulation. Authors directly centrifuge the blood and waited up to two days. After coagulating the blood it was centrifuged to separate the autologous serum for 10 minutes at $5000 \mathrm{rpm}$. The time and power of centrifugation is important in producing the amount of autologous serum without producing hemolysis and on the contrary, it is considered that with less centrifugal force or less time not only less serum is obtained but it can retain remains of platelet membranes which, if the dosage is large enough, can cause cell apoptosis. After separating the serum, authors go on to prepare the eye drops with fresh serum or store it in test tubes shielded from light by aluminum paper. Most prepared all the autologous serum eye drops with fresh serum, giving the flasks to the patient for their utilization, recommending them to keep the one in use in the refrigerator at $4^{\circ} \mathrm{C}$ and storing the rest at $-20^{\circ} \mathrm{C}$. The utilization of $20 \%$ concentration of autologous serum is empirical, in fact no significant differences have been found between the migration of epithelial cells of in vitro cultures with concentration between $10 \%$ and $20 \%$. Some authors believe that the greater concentration would have more effect on the eye surface. These authors utilize concentrations of $50 \%$ and $100 \%$. The most standardized utilization of autologous serum is at concentration of $20 \%$ or $50 \%$. This concentration seems sufficient and avoids the irritations derived from the higher viscosity of highly concentrated preparations, and considerably reduces the number of blood extractions. The number of applications varies from once every hour to three times a day (instillations every 2-3 hours and utilize the same flask for one week). Patients in this study used $50 \%$ autologous serum, one every 2-3 hours, during day and the same flask was used for seven days. Authors haven't had any case of conjunctivitis or corneal infections due to the application of autologous serum eye drops. For patients in study the autologous serum was obtained from the Clinic for Transfusion.

The statistical analyzes done by SPSS program versus 19 (by the Chi-Square test; $p$ values are calculated with significant level of 0.05 ).

\section{Results}

A total of the 116 eyes from the 93 patients (51 males and 42 females; aged between of min - 18 and max - 74) failed conventional topical medical therapy for treatment of the corneal epithelial defects and were treated with $50 \%$ autologous serum eye-drops to every 2 hours while awake.

The median time duration of the epithelial defects prior to initiation of autologous serum eye drops was 4.63 weeks. After institution of autologous serum therapy, 56 of the 116 eyes healed in the mean time of 28.1 days. The $56(48.28 \%)$ of eyes healed within 4 weeks of starting therapy with $50 \%$ autologous serum eye drops. The number of days required for healing was associated with the length of time the defect was open prior to initiation of serum drops.

Among the 116 eyes, the epithelial defect healed in $4(3.45 \%)$ within 1 week, in an additional 17 $(14.65 \%)$ in $1-2$ weeks, the totaling $31(26.72 \%)$ within 3 weeks. Five eyes $(4.31 \%)$ did completely heal at the 5 week; 6 eyes $(2.59 \%)$ had subsequent healing of the discrete epithelial defect at the 6 week; 56 eyes completely healed within one month, and the remaining 8 eyes healed within 1.5 month. The time period of autologous serum treatment ranged from 7 42 (10+/-3 days).

Authors proved that there was no statistically 
significant difference between the number of gender in our hospitalized patients with chemical injuries of the eyes $\left(x^{2}=1.301, p=0.254\right)$ (Table 1$)$.

Table 1: Frequency of chemical eye injuries by age groups and gender.

\begin{tabular}{|c|c|c|c|}
\hline \multirow{2}{*}{ Age groups } & \multicolumn{2}{|c|}{ Gender } & \multirow[b]{2}{*}{$\Sigma$} \\
\hline & Male & Female & \\
\hline $18-32$ & 15 & 16 & 31 \\
\hline $33-46$ & 17 & 13 & 30 \\
\hline $47-60$ & 16 & 10 & 26 \\
\hline $61-74$ & 4 & 2 & 6 \\
\hline Total & 52 & 41 & 93 \\
\hline
\end{tabular}

Authors proved that there were no statistically significant differences between the age groups of patients and distribution of the time of complete epithelialization defect in the cornea by the number of weeks to during the healing process $\left(x^{2}=22.334, p=\right.$ 0.099). We showed that the healing time was statistical significant and associated with young age groups $\left(x^{2}=17.667, p=0.001\right)$ (Table 2).

Table 2: Correlation between age groups and the length of healing.

\begin{tabular}{lccccccc}
\hline \multirow{2}{*}{ Age groups } & \multicolumn{8}{c}{ Number of weeks the length healing } \\
\cline { 2 - 8 } & 0 & $\mathrm{I}$ & II & III & IV & V & VI \\
\hline $18-32$ & 31 & 3 & 4 & 9 & 14 & 1 & 0 \\
$33-46$ & 30 & 4 & 4 & 9 & 12 & 0 & 1 \\
$47-60$ & 26 & 1 & 3 & 6 & 13 & 2 & 1 \\
$61-74$ & 6 & 0 & 0 & 3 & 0 & 2 & 1 \\
4 groups & 93 & 8 & 11 & 27 & 39 & 5 & 3 \\
\hline
\end{tabular}

We had also shown that the time of complete epithelialization defects of cornea lasted until 6 weeks ( $\mathrm{fl}+$ / - as well as clinical signs of epithelialization) and was high statistical significant differences in the second, the third and the fourth week of hospitalization (number of the eyes) and in most of our patients $\left(x^{2}=319.508, p<0.01\right)$ (Table 3$)$.

Table 3: The correlation between the size of defect and the length of healing.

\begin{tabular}{lccccccc}
\hline $\begin{array}{c}\text { Clinical signs } \\
\text { (size of defect) }\end{array}$ & \multicolumn{7}{c}{ Number of weeks length of healing } \\
\hline & 0 & I & II & III & IV & V & VI \\
\hline $\mathrm{FI}+++$ & 107 & 90 & 49 & 1 & 0 & 0 & 0 \\
$\mathrm{FI}++$ & 5 & 5 & 15 & 7 & 3 & 0 & 0 \\
$\mathrm{FL}+$ & 4 & 12 & 19 & 8 & 4 & 1 & 0 \\
$\mathrm{FI}+/$ & 0 & 5 & 12 & 48 & 4 & 2 & 0 \\
$\mathrm{FI} \varnothing$ & 0 & 4 & 17 & 31 & 56 & 5 & 3 \\
$\quad$ Total ayes & 116 & 116 & 112 & 95 & 64 & 8 & 3 \\
\hline
\end{tabular}

Clinical manifestations and slit-lamp exam of findings were in relation to the severity of the keratopathy. Many patients showed the subjective improvement of keratopathy symptoms after the autologous serum applications. None of the samples examined showed signs of bacterial or fungal infection or allergic irritation. There were no local side effects from autologous serum therapy.

The corneal epithelialization, corneal epithelial cell squamous metaplasia and tear stability improved significantly with the therapy, but the visual acuity, regression of vascular pannus and subepithelial scarring showed only slight improvement with this treatment.

\section{Discussion}

Authors correlated the median time duration of the epithelialization of defects due to usage of autologous serum eye drops with rate of epithelial healing. Using autologous serum eye drops it was managed to reduce the time of healing from eleven weeks (2.5 mounts), which were necessary just couple years ago (before 2010) to four (maximum six 1.5 mount) weeks to complete healing which are necessary today.

After the treatment there were no indications for surgical therapy such as penetrating keratoplasty, conjunctiva-plastic, amniotic membrane transplantation, etc.

The clinical studies (personal experience and literature reviews) performed showed a variable efficacy with the preparative process and the use of autologous serum eye drops varying considerably between the different studies including this study, too [2].

The use of $50 \%$ autologous serum eye drops appears to be an efficacious treatment modality for persistent corneal epithelial defects that are recalcitrant to conventional therapy [3], what this study proved.

In patients for whom serum treatment is indicated, but autologous serum is unavailable or unsuitable for use, the allogeneic serum offers an alternative option for therapy [4], what was not the cases in this study.

Platelet-rich plasma harbors with high concentrations of growth factors related to the promotion of many types wound healing. It could be an effective treatment option for chronic ocular surface disease and other similar diseases as our post-causoma injures [5].

A clinical pilot study was carried out to examine potential uses and in vitro toxicity testing on corneal epithelial cell cultures was performed to compare the effect of serum drops with unpreserved hypromellose (hydroxypropylmethylcellulose). In vitro toxicity testing demonstrated that serum drops have reduced toxicity compared with unpreserved hypromellose [6], but patients in our study applied only autologous serum without use of hypromellose or similar products.

Autologous serum eye drops were found effective in the treatment of severe dry eye diseases and others corneal problems as evidenced by improvement of tear stability and ocular surface vital staining scores [7].

Some studies showed the effect of autologous serum eye drop application in the aniridic keratopathy. Autologous serum eye drops improved aniridic keratopathy in patients with light or moderate severity. 
In these patients, use of autologous serum eye drops was superior to conventional therapy with substitute tears for improving the ocular surface and the subjective comfort [8].

Eye drops prepared from autologous serum are a relative new treatment option for severe ocular surface disease. It supports the migration of corneal epithelial cells and the differentiation of conjunctiva epithelial cells. Methodological variations determine the biochemical properties and thus the known epitheliotrophic effect of serum eye drops [1].

Effectiveness of serum treatment has been proven for many diseases: chemical eye injuries, keratoconjunctivitis sicca, superior limbic keratoconjunctivitis, recurrent erosion syndrome and persistent epithelial defects. A unified standard of preparing the autologous serum eye drops has not been elaborated and in various publications different modes of preparation of the solution have been used. It is important to document indications for this treatment appropriately, as well as to be cautious while preparing and using the solution [9].

Authors review showed the mechanisms responsible for maintenance of corneal homeostasis as well as the development the modes of treatment for various corneal diseases. The resident cells of the cornea-epithelial cells, fibroblasts and endothelial cells also engage in mutual interactions through the network systems. In seeking an alternative to fibronectin eye drops, authors were investigating the effects of a peptide corresponding to the second cellbinding domain of fibronectin on corneal epithelial wound healing. Triptolide or its derivatives are thus potential drugs for the treatment of corneal ulcer and would work by acting directly on corneal fibroblasts rather than by inhibiting the secreted enzymes (matrix metalloproteinase) responsible for collagen degradation [10].

The other study of the impact of topical treatment with autologous serum on the clinical evolution of persistent corneal epithelial defects, observed its effect on the squamous metaplasia in cases of dry eye. Autologous serum treatment accelerates healing and application causes an involution of squamous metaplasia [11].

Autologous serum was prepared from the patients, diluted to $20 \%$ and used six to ten times a day. The concentration of vitamin $A$, epidermal growth factor and transforming growth factor-beta was measured at 1 week and 1 month (stored in the refrigerator and 1 month and 3 months in the freezer) [12], but we, serum used by patients in this study prepared and stored in a different way, it was obtained from the patients and diluted to $50 \%$ and patients were instructed to use is once every $2-3$ hours, but it was stored in refrigerator on $4^{\circ} \mathrm{C}$ for seven days.

Authors determine the efficacy of autologous serum drops in the treatment of superior limbic keratoconjunctivitis. Autologous serum application can be used as an alternative mode of therapy in this and known corneal pathology [13].

Authors studied the effect of topical fibronectin on epithelial injures healing and ulceration in alkaliburned the rabbit corneas. Fibronectin accelerated the complete surface re-epithelialization. A prominent fibronectin-fibrinogen matrix remained on the surface of fibronectin-treated corneas, presumably aiding surface re-epithelialization and decreasing corneal ulceration [14].

Clinical studies showed a variable efficacy of serum approach, but the parameters for the production of blood product varied significantly. Clotting time, centrifugation and diluents have the significant impact on the composition and epitheliotrophic effects of the serum [15].

Expose shoved the elaboration process: microbiological control and effectiveness of eyewash prepared with the patient's serum for the treatment of injure corneas of different etiology. The eyewashes got ready under sterile conditions, using the patient's serum diluted to $20 \%$ with physiologic solution in the treatment in serious cases of chemical injures, dry eye, corneal ulceration [16], whose experience we do not share.

Investigate the sterility of non-preserved autologous serum drops in hospitalized patients with persistent corneal epithelial defects was conducted using blood, chocolate, endow, and Sabouraud agar media, the sterility of autologous serum drops was assessed on the day before application and on the $4^{\text {th }}$ and $7^{\text {th }}$ days. Patients had received topical autologous serum therapy and prophylactic antibiotic drops for at least 7 days. By additional application of prophylactic antibiotic drops, infections may be avoided even if refrigerated non-preserved autologous serum is used up to 7 days [17], what authors applied on patient in this study.

As a conclusion, the application of autologous serum eye drops has proven to be effective, practicable and safe therapy in patients with postcausoma corneal persistent epithelial defects. Using serum therapy, it was managed to reduce the time of healing from eleven weeks, which were necessary just couple years ago (before 2010) to four (maximum six) weeks to complete healing which are necessary today.

\section{References}

1. Geerling G, Hartwig D. Autologous serum eye drops for ocular surface disorders. A literature review and recommendations for their application. Ophthalmologe. 2002; 99(12):949-59.

2. López-García JS, García-Lozano I, Rivas L, MartínezGarchitorena J. Use of autologous serum in ophthalmic practice. Arch Soc Esp Oftalmol. 2007; 82(1):9-20.

3. Jeng $\mathrm{BH}$, Dupps WJ Jr. Autologous serum $50 \%$ eye drops in 
the treatment of persistent corneal epithelial defects. Cornea. 2009; 28(10):1104-8.

4. Chiang CC, Chen WL, Lin JM, Tsai YY. Allogeneic serum eye drops for the treatment of persistent corneal epithelial defect. Eye (Lond). 2009; 23(2):290-3.

5. Kim KM, Shin YT, Kim HK. Effect of autologous platelet-rich plasma on persistent corneal epithelial defect after infectious keratitis. Jpn J Ophthalmol. 2012; 56(6):544-50.

6. Poon AC, Geerling G, Dart JK, Fraenkel GE, Daniels JT. Autologous serum eye drops for dry eyes and epithelial defects: clinical and in vitro toxicity studies. $\mathrm{Br} \mathrm{J}$ Ophthalmol. 2001; 85(10):1188-97.

7. Kojima $T$, Ishida R, Dogru M, Goto E, Matsumoto $Y$, Kaido M, Tsubota K. The effect of autologous serum eye drops in the treatment of severe dry eye disease: a prospective randomized case-control study. Am J Ophthalmol. 2005; 139(2):242-6.

8. López-García JS, Rivas L, García-Lozano I, Murube J. Autologous serum eye drops in the treatment of aniridic keratopathy. Ophthalmology. 2008; 115(2):262-7.

9. Wilczyński M. The use of autologous serum in the treatment of the ocular surface diseases. Klin Oczna. 2009; 111(10-12):363-8.

10. Nishida T. The cornea: stasis and dynamics. Nihon Ganka Gakkai Zasshi. 2008; 112(3):179-212.

11. Alvarado Valero MC, Martínez Toldos JJ, Borras Blasco J, Almiñana Almiñana A, Pérez Ramos JM. Treatment of persistent epithelial defects using autologous serum application. Arch Soc Esp Oftalmol. 2004; 79(11):537-42.

12. Tsubota K, Goto E, Shimmura S, Shimazaki J. Treatment of persistent corneal epithelial defect by autologous serum application. Ophthalmology. 1999; 106(10):1984-9.

13. Goto E, Shimmura S, Shimazaki J, Tsubota K. Treatment of superior limbic keratoconjunctivitis by application of autologous serum. Cornea. 2001; 20(8):807-10.

14. Phan TM, Foster CS, Shaw CD, Zagachin LM, Colvin RB Topical fibronectin in an alkali burn model of corneal ulceration in rabbits. Arch Ophthalmol. 1991; 109(3):414-9.

15. Liu L, Hartwig D, Harloff S, Herminghaus P, Wedel T, Geerling $\mathrm{G}$. An optimised protocol for the production of autologous serum eye drops. Graefes Arch Clin Exp Ophthalmol. 2005; 243(7):70614.

16. García Jiménez V, Veiga Villaverde B, Baamonde Arbaiza B, Cahue Carpintero I, Celemín Viñuela ML, Simó Martínez RM. The elaboration, use and evaluation of eye-drops with autologous serum in corneal lesions. Farm Hosp. 2003; 27(1):21-5.

17. Sauer R, Blüthner K, Seitz B. Sterility of non-preserved autologous serum drops for treatment of persistent corneal epithelial defects. Ophthalmologe. 2004; 101(7):705-9. 